\title{
Evaluation of postoperative quality of life by PGSAS-45 following local gastrectomy based on the sentinel lymph node concept in early gastric cancer
}

\author{
Keishi Okubo ${ }^{1} \cdot$ Takaaki Arigami $^{2} \cdot$ Daisuke Matsushita $^{1} \cdot$ Ken Sasaki $^{1} \cdot$ Takashi Kijima $^{1} \cdot$ Masahiro Noda $^{1}$. \\ Yoshikazu Uenosono $^{1}$ - Shigehiro Yanagita ${ }^{1}$. Sumiya Ishigami $^{1} \cdot$ Kosei Maemura $^{1}$ - Shoji Natsugoe ${ }^{1,2}$
}

Received: 16 December 2019 / Accepted: 6 February 2020 / Published online: 21 February 2020

(c) The International Gastric Cancer Association and The Japanese Gastric Cancer Association 2020

\begin{abstract}
Background The usefulness of sentinel node navigation surgery (SNNS) for early gastric cancer has been demonstrated in a multicenter prospective study. However, quality of life (QOL) after local resection remains unclear. This present study investigated QOL after local resection and distal gastrectomy.

Methods We examined 69 patients who underwent laparoscopic distal gastrectomy (LADG) $(n=44)$ and laparoscopic local resection (LLR) $(n=25)$ in our hospital between September 2011 and May 2018. We conducted a combination of laparoscopic and endoscopic approaches to neoplasia with non-exposure technique (CLEAN-NET) with SNNS as LLR. All patients had pStage I or II and none had received adjuvant chemotherapy. We evaluated QOL using the postgastrectomy syndrome assessment scale questionnaire (PGSAS-45) 1, 6, and 12 months after surgery.

Results In PGSAS-45, no significant differences were observed between LLR and LADG at 1 and 6 months after surgery. At 12 months, the LLR group scored better for some of the subscales (SS). In the endoscopic evaluation, the LLR group showed significant improvements in residual gastritis at 6 months $(P=0.006)$ and esophageal reflux and residual gastritis at 12 months $(P=0.021$ and $P=0.017)$. A significant difference was observed in the prognostic nutritional index, which was assessed using serum samples, between the two groups at 6 months $(P=0.028)$. The body weight ratio was better in the LLR group than in the LADG group at 6 and 12 months $(P=0.041$ and $P=0.007$, respectively).

Conclusions CLEAN-NET with SNNS preserved a better QOL and nutrition status than LADG in patients with early gastric cancer.
\end{abstract}

Keywords Gastric cancer · PGSAS-45 · CLEAN-NET · Sentinel node navigation surgery

\section{Introduction}

Gastric cancer is one of the most common malignancies and patients with advanced gastric cancer have a poor prognosis. Gastric cancer is now being detected in the early stages in many cases due to recent advances in endoscopic diagnoses.

Keishi Okubo

ok0627@m2.kufm.kagoshima-u.ac.jp

1 Department of Digestive Surgery, Breast and Thyroid Surgery, Kagoshima University Graduate School of Medical and Dental Sciences, 8-35-1 Sakuragaoka, Kagoshima 890-8520, Japan

2 Department of Onco-Biological Surgery, Kagoshima University Graduate School of Medical and Dental Sciences, Kagoshima, Japan
Endoscopic mucosal resection and endoscopic submucosal dissection (ESD) are currently only performed on patients with early gastric cancer. However, standard gastrectomy with lymphadenectomy is recommended for histologically undifferentiated-type adenocarcinomas and submucosal tumors. The sentinel node ( $\mathrm{SN}$ ) is defined as the first draining lymph node that receives lymphatic flow from the primary tumor. The SN concept has been analyzed in several facilities to prove that sentinel node navigation surgery (SNNS) is a safe and minimally invasive surgery for patients who need to undergo standard lymphadenectomy [1,2]. In 2000 , the SN concept for gastric cancer was initially introduced in Japanese studies [3, 4]. We detected SN in 78 (99\%) out of 79 patients with cT1N0 tumors by ${ }^{99 \mathrm{~m}} \mathrm{Tc}$-radiolabeled tin colloid methods, with sensitivity and accuracy rates of $100 \%$ [5]. A prospective multicenter trial on SN mapping 
for gastric cancer (cT1 and T2) in Japan demonstrated that SNNS with basic radioisotope (RI) method is a feasible procedure [6]. In this study, basin dissection by the dual tracer of RI and dye-guided method was confirmed to be safe and effective for small T1 or T2 gastric adenocarcinoma. SNNS in early gastric cancer may preserve the function and volume of the remnant stomach. However, it currently remains unclear whether function-preserving gastrectomy based on the $\mathrm{SN}$ concept is superior to conventional gastrectomy, such as laparoscopic distal gastrectomy (LADG), for maintaining quality of life (QOL) after surgery.

Postgastrectomy syndrome assessment scale (PGSAS)-45 was designed to assess the symptoms, living status, and QOL of patients after gastrectomy [7]. It consists of 45 items, 22 are original items and 23 were retrieved from the ShortForm Health Survey (SF-8) and Gastrointestinal Symptom Rating Scale questionnaires with permission. Previous studies reported the assessment of QOL after gastrectomy using PGSAS questionnaire [8-11].

The prognostic nutritional index (PNI) assesses the nutritional and immunological status [12]. The PNI is calculated from serum albumin level and peripheral lymphocyte counts. It is used to predict the outcomes of patients with various malignancies [13-17]. PNI is valuable to assess the objective evaluation of nutrition status.

There are few studies assessing the QOL and nutrition status after laparoscopic local resection (LLR) with SNNS.

In the present study, we investigated QOL using PGSAS45 and the nutritional status using PNI after function-preserving gastrectomy by SNNS for early gastric cancer.

\section{Materials and methods}

\section{Patients}

This was a retrospective study and included 29 patients receiving a combination of laparoscopic and endoscopic approaches to neoplasia with non-exposure technique (CLEAN-NET) with SNNS as LLR and 74 patients receiving LADG between September 2011 and May 2018 at Kagoshima University Hospital, Kagoshima, Japan. All patients had pStage I or II gastric cancer and had not received adjuvant chemotherapy. We evaluated QOL using PGSAS-45 at 1, 6, and 12 months after surgery. Out of 29 patients receiving LLR, 25 patients who submitted PGSAS-45 questionnaire at 12 months were evaluated. Among those evaluated, QOL of 15 patients and gastroscopy of 13 patients could be assessed at 1 and 6 months. Likewise, among 74 patients receiving LADG, only 44 patients who submitted PGSAS-45 questionnaire at 12 months were evaluated. In this group, we could assess QOL of 18 patients and gastroscopy of 27 patients at 1 and 6 months (Fig. 1). Patients who were unable to complete the questionnaires were excluded.

The Ethics Committee at Kagoshima University approved this study and all patients provided written informed consent for the use of their information.

\section{CLEAN-NET based on SNNS}

Twenty-five patients with early gastric cancer, diagnosed as cT1N0M0 with tumors $\leq 40 \mathrm{~mm}$, were retrospectively reviewed for CLEAN-NET with SNNS as LLR. One day before surgery, $3 \mathrm{mCi}(2 \mathrm{ml})$ of ${ }^{99 \mathrm{~m}} \mathrm{Tech}$ etium-Tin colloid was endoscopically injected into the submucosa at four sites $(0.5 \mathrm{ml}$ each) around the tumor. Indocyanine green (ICG) was similarly injected before surgery. During surgery, RI uptake by each lymph node was measured using Navigator GPS (Tyco Healthcare, Ltd., Tokyo, Japan) and ICG fluorescence was identified by an infrared imaging system (OLYMPUS Corporation., Tokyo Japan). These patients were classified as the LLR group in the present study. Informed consent was obtained from all patients based on a document approved by the Ethics Committee of the hospital. All patients underwent computed tomography, endoscopy, fluoroscopy, endoscopic ultrasonography, and ultrasonography before surgery.

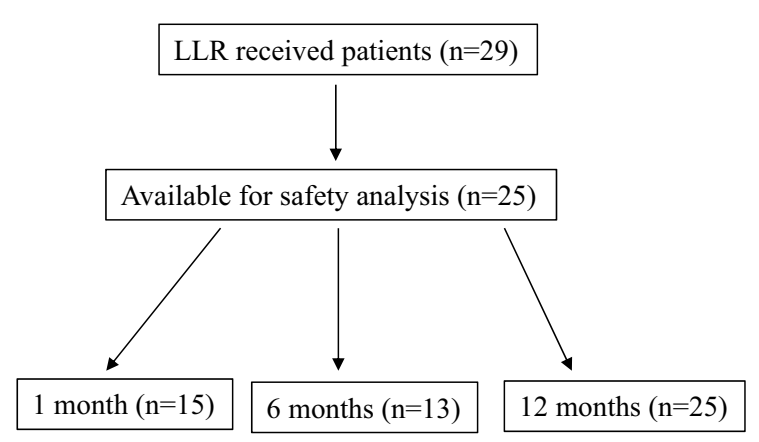

Fig. 1 CONSORT flow diagram 


\section{Assessment of postoperative QOL and the remnant stomach status}

PGSAS-45 is a newly developed set of integrated questionnaires specifically designed to assess postoperative symptoms and QOL after gastrectomy. The main outcome measures (MOMs) of PGSAS-45 comprise seven symptom scales (esophageal reflux, abdominal pain, meal-related distress, indigestion, diarrhea, constipation, and dumping), four living status scales (ingested amount of food per meal, necessity for additional food, quality of ingestion, and ability for working), and one QOL scale (dissatisfaction with daily life).

We conducted endoscopy 1,6 , and 12 months after gastrectomy and evaluated the status of the gastric residue, esophageal reflux, and residual gastritis.

\section{Evaluation of changes in body weight and PNI}

Changes in body weight (body weight ratio) were calculated using the following formula: present body weight/ preoperative body weight $\times 100(\%)$. PNI was calculated as $10 \times$ serum albumin $(\mathrm{g} / \mathrm{dl})+0.005 \times$ total lymphocyte count $\left(\right.$ per $\left.\mathrm{mm}^{3}\right)$ [12].

\section{Statistical analysis}

Statistical analyses of group differences were performed using the $\chi^{2}$ test and $t$ test. All statistical calculations were performed using SAS statistical software (SAS Institute. Inc., Cary, NC). A $P$ value of $<0.05$ was considered to be significant.

\section{Results}

\section{Patient characteristics}

Patient characteristics are shown in Table 1. All patients had pStage I or II gastric cancer. Tumor sizes were smaller, operation time was shorter, and blood loss was lesser in the LLR group than in the LADG group $(P=0.004, P=0.027$, and $P=0.031$, respectively). The number of dissected lymph nodes was significantly smaller in the LLR group than in the LADG group $(P<0.0001)$.

\section{Evaluation by PGSAS-45}

Table 2, 3, and 4 show the results of a multiple regression analysis of PGSAS MOMs 1, 6, and 12 months after gastrectomy. No significant differences were observed in any symptom MOMs between the two groups 1 and 66 months
Table 1 Clinicopathological characteristics of patients

\begin{tabular}{|c|c|c|c|}
\hline & $\operatorname{LLR}(n=25)$ & LADG $(n=44)$ & $P$ value \\
\hline \multicolumn{4}{|l|}{ Gender } \\
\hline Male & 12 & 30 & 0.126 \\
\hline Female & 13 & 14 & \\
\hline Age & $67.28(40-81)$ & $68.95(42-91)$ & 0.247 \\
\hline \multicolumn{4}{|l|}{ pT factor } \\
\hline $\mathrm{T} 1-2$ & 25 & 42 & \\
\hline T3-4 & 0 & 2 & \\
\hline \multicolumn{4}{|l|}{ Location } \\
\hline $\mathrm{U}$ & 3 & 2 & \\
\hline M & 19 & 20 & \\
\hline $\mathrm{L}$ & 3 & 22 & \\
\hline \multicolumn{4}{|l|}{$\mathrm{pN}$ factor } \\
\hline No & 24 & 43 & \\
\hline $\mathrm{N} 1-3$ & 1 & 1 & \\
\hline \multicolumn{4}{|l|}{ pStage } \\
\hline I & 25 & 42 & \\
\hline II & 0 & 2 & \\
\hline \multicolumn{4}{|c|}{ Histopathological type } \\
\hline Differ & 11 & 25 & \\
\hline Undiffer & 14 & 19 & \\
\hline Tumor size (mm) & $18.49 \pm 2.77$ & $30.65 \pm 2.09$ & 0.0004 \\
\hline Operation time & $325.80 \pm 17.72$ & $369.3 \pm 13.35$ & 0.027 \\
\hline Blood loss & $30.8 \pm 28.37$ & $98.18 \pm 21.38$ & 0.031 \\
\hline $\begin{array}{l}\text { Number of lymph } \\
\text { node dissection }\end{array}$ & $15.76 \pm 1.92$ & $27.13 \pm 1.45$ & $<0.0001$ \\
\hline
\end{tabular}

$L L R$ laparoscopic local resection

after gastrectomy. The "indigestion symptom subscale (SS)", "ingestion amount of food per meal", "necessity for additional", "dissatisfaction at the meals", and "dissatisfaction for daily life" were better in the LLR group than in the LADG group 12 months after gastrectomy $(P=0.013$, $P<0.0001, P=0.03, P=0.007$, and $P=0.045$, respectively). MOM changes from 1 to 12 months in the LLR and LADG groups are shown in Fig. 2. In the LLR group, the "quality of the ingestion SS" and "ingested amount of food per meal" improved over time.

\section{Evaluation by endoscopy}

We compared the status of the gastric residue, esophageal reflux, and residual gastritis 1, 6, and 12 months after gastrectomy between the LLR and LADG groups. The LLR group showed significant improvements in residual gastritis at 6 months and esophageal reflux and residual gastritis 
Table 2 Scores of the PGSAS45 symptoms at one months after gastrectomy
Table 3 Scores of the PGSAS45 symptoms at 6 months after gastrectomy
Table 4 Scores of the PGSAS45 symptoms at 12 months after gastrectomy

\begin{tabular}{lllll}
\hline MOMs & LLR group & LADG group & $P$ & Cohen's $d$ value \\
\hline Esophageal reflux SS & $1.70 \pm 0.578$ & $1.54 \pm 0.515$ & 0.412 & 0.30 \\
Abdominal pain SS & $1.71 \pm 0.594$ & $1.69 \pm 0.757$ & 0.933 & 0.03 \\
Meal-related distress SS & $1.80 \pm 0.568$ & $2.04 \pm 0.727$ & 0.296 & 0.38 \\
Indigestion SS & $1.77 \pm 0.451$ & $1.74 \pm 0.510$ & 0.859 & 0.06 \\
Diarrhea SS & $1.38 \pm 0.419$ & $1.43 \pm 0.530$ & 0.764 & 0.11 \\
Constipation SS & $2.38 \pm 1.234$ & $2.00 \pm 0.753$ & 0.306 & 0.39 \\
Dumping SS & $2.28 \pm 1.010$ & $2.23 \pm 1.019$ & 0.889 & 0.05 \\
Ingestion amount of food & $6.50 \pm 2.175$ & $5.14 \pm 2.222$ & 0.086 & 0.64 \\
Necessity for additional food & $2.13 \pm 1.146$ & $2.33 \pm 0.745$ & 0.565 & 0.22 \\
Quality of ingestion SS & $3.40 \pm 0.573$ & $3.72 \pm 0.897$ & 0.224 & 0.43 \\
Dissatisfaction at meal & $2.60 \pm 1.143$ & $3.18 \pm 1.149$ & 0.158 & 0.52 \\
Dissatisfaction for daily life & $2.11 \pm 0.891$ & $2.22 \pm 0.993$ & 0.740 & 0.12 \\
\hline
\end{tabular}

MOMs main outcome measures, SS subscale

\begin{tabular}{lllll}
\hline MOMs & LLR group & LADG group & $P$ & Cohen's $d$ value \\
\hline Esophageal reflux SS & $1.52 \pm 0.532$ & $1.43 \pm 0.564$ & 0.589 & 0.17 \\
Abdominal pain SS & $1.62 \pm 0.664$ & $1.74 \pm 0.733$ & 0.608 & 0.17 \\
Meal-related distress SS & $1.56 \pm 0.696$ & $1.79 \pm 0.861$ & 0.371 & 0.29 \\
Indigestion SS & $1.65 \pm 0.710$ & $1.64 \pm 0.856$ & 0.969 & 0.01 \\
Diarrhea SS & $1.38 \pm 0.520$ & $1.85 \pm 1.290$ & 0.110 & 0.44 \\
Constipation SS & $1.69 \pm 0.697$ & $1.75 \pm 0.745$ & 0.804 & 0.08 \\
Dumping SS & $1.41 \pm 1.047$ & $1.51 \pm 1.183$ & 0.788 & 0.09 \\
Ingestion amount of food & $8.15 \pm 1.291$ & $7.17 \pm 2.093$ & 0.077 & 0.54 \\
Necessity for additional food & $1.54 \pm 0.634$ & $1.96 \pm 0.792$ & 0.079 & 0.58 \\
Quality of ingestion SS & $4.00 \pm 0.584$ & $3.63 \pm 0.857$ & 0.118 & 0.49 \\
Dissatisfaction at meal & $1.69 \pm 0.821$ & $2.15 \pm 1.145$ & 0.155 & 0.45 \\
Dissatisfaction for daily life & $1.46 \pm 0.498$ & $1.86 \pm 0.903$ & 0.079 & 0.51 \\
\hline
\end{tabular}

MOMs main outcome measures, SS subscale

\begin{tabular}{lllll}
\hline MOMs & LLR group & LADG group & $P$ & Cohen's $d$ value \\
\hline Esophageal reflux SS & $1.37 \pm 0.449$ & $1.51 \pm 0.622$ & 0.285 & 0.25 \\
Abdominal pain SS & $1.40 \pm 0.573$ & $1.45 \pm 0.598$ & 0.733 & 0.09 \\
Meal-related distress SS & $1.45 \pm 0.497$ & $1.77 \pm 0.860$ & 0.054 & 0.43 \\
Indigestion SS & $1.35 \pm 0.503$ & $1.72 \pm 0.694$ & 0.013 & 0.59 \\
Diarrhea SS & $1.63 \pm 0.627$ & $1.72 \pm 0.989$ & 0.646 & 0.10 \\
Constipation SS & $1.64 \pm 0.771$ & $1.58 \pm 0.640$ & 0.743 & 0.09 \\
Dumping SS & $1.64 \pm 0.771$ & $2.11 \pm 1.189$ & 0.051 & 0.45 \\
Ingestion amount of food & $8.70 \pm 1.000$ & $7.36 \pm 1.852$ & $<0.0001$ & 0.85 \\
Necessity for additional food & $1.42 \pm 0.560$ & $1.77 \pm 0.742$ & 0.030 & 0.52 \\
Quality of ingestion SS & $3.92 \pm 0.839$ & $3.72 \pm 0.945$ & 0.367 & 0.22 \\
Dissatisfaction at meal & $1.32 \pm 0.614$ & $1.93 \pm 1.208$ & 0.007 & 0.60 \\
Dissatisfaction for daily life & $1.28 \pm 0.468$ & $1.58 \pm 0.749$ & 0.045 & 0.46 \\
\hline
\end{tabular}

MOMs main outcome measures, SS subscale 
Fig. 2 PGSAS-45 from 1 to 12 months in LLR and LADG groups
Esophageal reflux SS

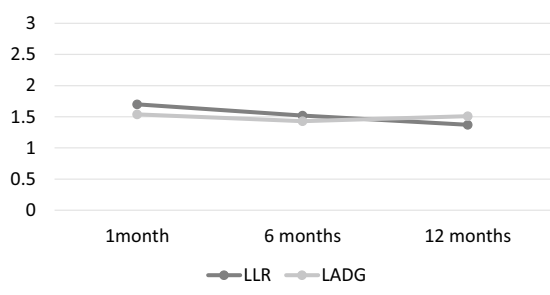

Meal-related distress SS

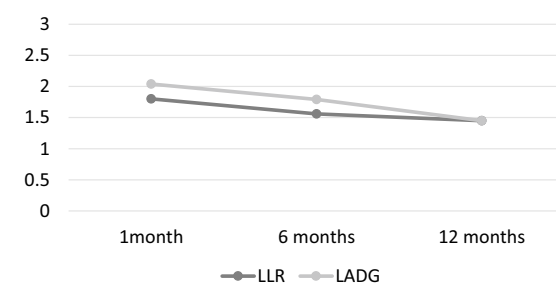

Diarrhea SS

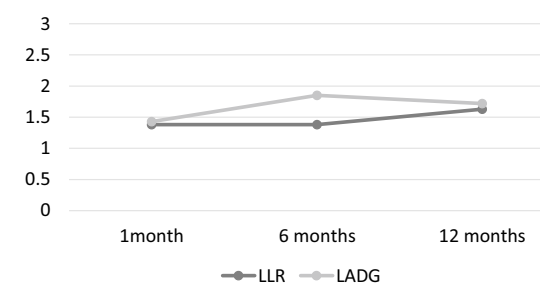

Dumping SS

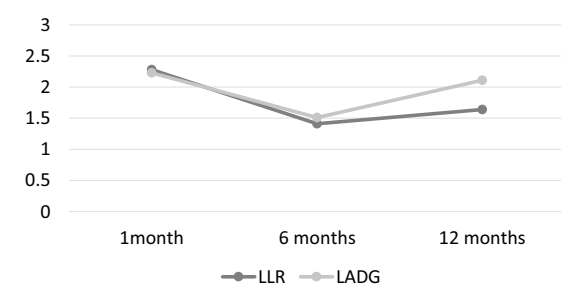

Dissatisfaction for daily life

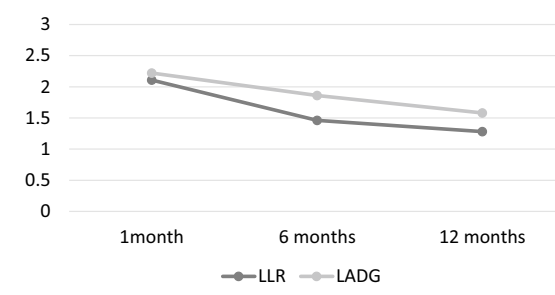

Dissatisfaction at meal

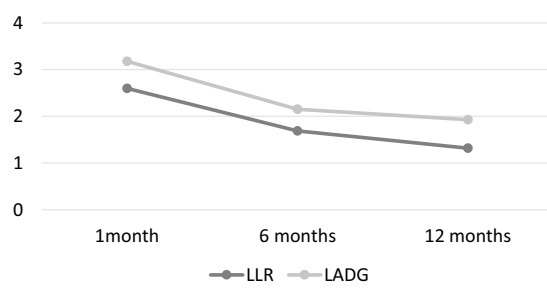

Abdominal pain SS

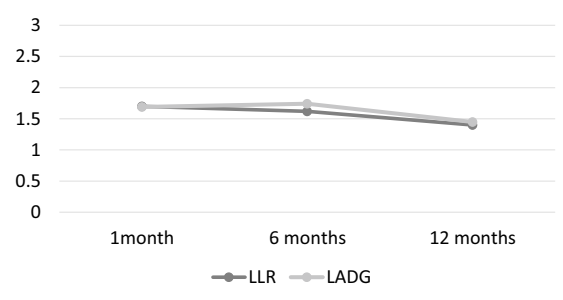

Indigestion SS

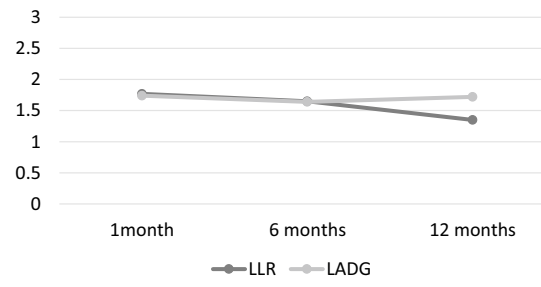

Constipation SS

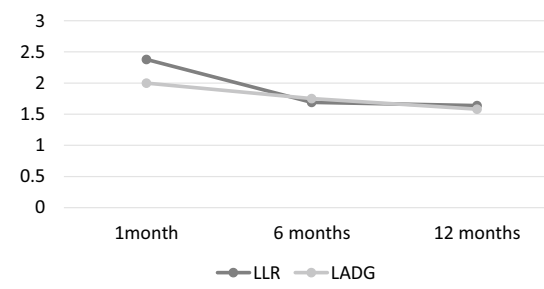

Quality of ingestion SS
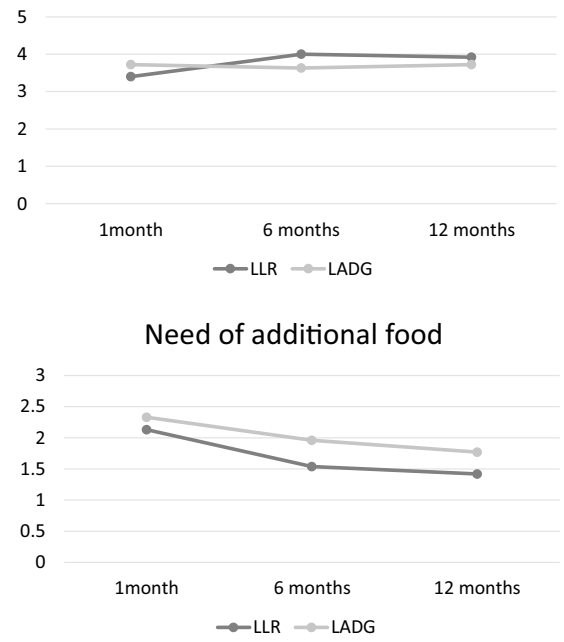

10

8

8

6

2

0 $\rightarrow$ LLR $\rightarrow-$ LADG

Need of additional food

Ingestion amount of food

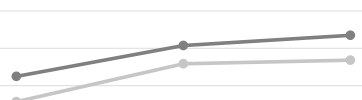

1month 6 months 12 months 
Table 5 Evaluation of remnant stomach status by endoscopy

\begin{tabular}{llll}
\hline Parameters & LLR $(\%)$ & LADG $(\%)$ & $P$ value \\
\hline Gastric residue & & & \\
$\quad 1$ month & 33.3 & 31.2 & 0.907 \\
6 months & 30.7 & 29.1 & 0.918 \\
$\quad 12$ months & 36.0 & 23.2 & 0.258 \\
Esophageal reflux & & & \\
$\quad 1$ month & 8.3 & 6.25 & 0.832 \\
6 months & 7.6 & 25.0 & 0.199 \\
12 months & 0 & 18.6 & 0.021 \\
Residual gastritis & & & \\
1 month & 16.6 & 50 & 0.068 \\
6 months & 15.3 & 62.5 & 0.006 \\
12 months & 24.0 & 53.4 & 0.017 \\
\hline
\end{tabular}

Table 6 Evaluation of body weight ration and PNI in LLR group and LADG group

\begin{tabular}{llll}
\hline Parameters & LLR & LADG & $P$ value \\
\hline PNI & & & \\
1 month & $51.53 \pm 2.00$ & $50.76 \pm 1.89$ & 0.967 \\
6 months & $53.34 \pm 1.34$ & $50.35 \pm 0.93$ & 0.028 \\
12 months & $51.32 \pm 1.19$ & $49.55 \pm 0.85$ & 0.229 \\
Body weight ratio & & & \\
1 month & $94.2 \pm 0.007$ & $94.0 \pm 0.007$ & 0.346 \\
6 months & $97.3 \pm 0.017$ & $93.2 \pm 0.012$ & 0.041 \\
12 months & $97.4 \pm 0.012$ & $93.0 \pm 0.009$ & 0.007 \\
\hline
\end{tabular}

PNI prognostic nutritional index

at 12 months $(P=0.006, P=0.021$, and $P=0.017$, respectively) (Table 5).

\section{Evaluation of changing body weights and nutritional indicators}

Body weight ratios in the LLR and LADG groups are shown in Table 6 . The body weight ratio was better in the LLR group than in the LADG group at 6 and 12 months $(P=0.041$ and $P=0.007$, respectively). It increased in the LLR group but decreased in the LADG group between 1 and 12 months.

PNI was significantly higher in the LLG group than in the LADG group at 6 months $(53.34 \pm 1.348$ and $50.357 \pm 0.938$, respectively; $P=0.028$ ).

\section{Discussion}

The frequency of nodal metastasis is $1-3 \%$ in mucosal cancer and 11-20\% in submucosal cancer [18]. These findings suggest that the majority of patients with early gastric cancer undergo unnecessary lymph node dissection. Although the clinical indications for ESD have been expanded, the Japanese Gastric Cancer Treatment Guidelines recommend lymph node dissection for patients meeting the non-indications for ESD [19]. In this background, SNNS has recently been developed as a minimally invasive approach with function-preserving surgery for patients with early gastric cancer [3, 4].

Goto et al. performed non-exposed endoscopic wallinversion surgery (NEWS) based on the SN concept on patients with early gastric cancer [20]. On the other hand, CLEAN-NET was initially reported by Inoue et al. in 2012 [21]. This surgical method has the clinical utility of a nonexposed approach as well as NEWS. In CLEAN-NET, the seromuscular layer is dissected from outside the stomach using a spatula-shaped electrocautery knife under laparoscopy and a full-thickness specimen including the tumor is dissected using a laparoscopic stapling device to prevent the risk of tumor dissemination caused by opening of the stomach [22]. We have performed CLEAN-NET with SN basin dissection on selected patients with cT1 and cN0 gastric cancer measuring $<4.0 \mathrm{~cm}$ in diameter [23]. However, QOL and the nutritional status after function-preserving gastrectomy by SNNS have not yet been assessed in patients with early gastric cancer. To the best of our knowledge, this is the first study to examine postgastrectomy syndrome between LLR based on the SN concept and conventional LADG.

Postgastrectomy symptoms occur after gastrectomy and several of these symptoms appear to worsen QOL. PGSAS-45 was newly developed by the Japanese Postgastrectomy Syndrome Working party (JPGSWP) to provide a valid and reliable integrated index for the evaluation of symptoms, living status, and QOL after gastrectomy. In recent years, QOL assessments using PGSAS-45 have been performed after gastrectomy [24, 25]. Accordingly, we herein adopted PGSAS-45 for a functional analysis after gastrectomy. In present study, LLR was superior to LADG for the "indigestion SS", "ingested amount of food per meal", "necessity for additional meals", "dissatisfaction at the meals", and "dissatisfaction for daily life SS". These results were only significantly different at 12 months after gastrectomy. We believe the difference in the clinical symptoms was from some reasons. The remnant stomach volume, gastroparesis and deformation after gastrectomy are associated with QOL and several symptoms. Remnant stomach volume is important for retention to prevent dumping syndrome. Hence, "dumping SS" and "ingested amount of food per meal" were better in the LLR group than LADG group. Delayed gastric emptying is caused by gastroparesis and deformation after gastrectomy. Since the LLR group had limited lymphadenectomy and the nerves around stomach were preserved, gastroparesis and deformation were lesser compared to LADG group. 
Hence, "indigestion SS", "necessity for additional meals" and "dissatisfaction at the meals" were significantly better in LLR group than in LADG group.

For a short period of time after surgery in the LLR group, patients were unable to eat the same amount of food as the preoperative amount. The remnant stomach after local resection may lose some functions due to deformation, similar to LADG. Moreover, endoscopic findings demonstrated that the gastric residue volume was similar between LLR and LADG 1 and 6 months after gastrectomy. This may be the main reason for the lack of significant differences in PGSAS45 symptom scores 1 and 6 months after surgery. Kobayashi et al. reported that the QOL of patients after gastrectomy had stabilized 1 year after surgery [26]. In the present study, esophageal reflux and residual gastritis were significantly better in the LLR group than in the LADG group 12 months after gastrectomy. Therefore, the LLR group had better outcomes for the amount of food ingested per meal, the body weight ratio, and PNI.

In this study, 11 out of 25 patients in LLR group had a lymphatic flow with sentinel node along the left gastric artery. In these cases, resection of No. 7 lymph node was performed and celiac branch of the vagal nerve (CBVN) was cut. CBVN was preserved in the remaining 14 patients. Therefore, the worse PGSAS-45 scores observed in the LADG group in the present study may depend on the loss of the CBVN. Kinami et al. showed that background factors in each patient affected postgastrectomy syndromes after gastrectomy [27]. They suggested that the preservation of the celiac branch in the vagus ameliorated postgastrectomy syndromes in patients undergoing distal gastrectomy (DG) and proximal gastrectomy. The PGSAS study, using a multivariate analysis, showed that preservation of the CBVN was significantly related to reduced weight loss after distal gastrectomy [8]. Also, Furukawa et al. reported that preservation of the CBVN in LPPG is of no clinical benefit [28]. Hence, the clinical benefit of preservation of CBVN remains unclear and further study is needed to clarify the role of the CBVN.

Isozaki et al. reported that local resection resulted in a better intake of food and QOL than DG [29]. They recommended local resection for patients with early gastric cancer in whom sentinel lymph nodes were observed in one lymphatic basin alone. Moreover, Kawamura et al. indicated that the reservoir capacity, gastric emptying, and QOL after local resection were maintained in the ${ }^{13} \mathrm{C}$ breath test [30]. Hence, the size of the gastric remnant may be closely associated with a better intake of food and QOL. Changed body weight is often used as an index which objectively evaluates the physical status of postgastrectomy patients and PNI is valuable to assess the objective evaluation of nutrition status. We think body weight ratio and PNI are affected by ingestion amount of food and several symptoms of postgastrectomy.
Hence, body weight ratio and PNI were better in LLR group than LADG group.

The present study had several limitations. This preliminary study consisted of a retrospective analysis of a small population $(n=69)$ from a single institution, which may have resulted in bias that influenced several results. Therefore, larger validation studies are needed to strengthen the present results.

In conclusion, we demonstrated that LLR with SNNS achieved superior results over LADG in terms of the "indigestion SS", "ingested amount of food per meals", "necessity for additional food", "dissatisfaction at the meals", and "dissatisfaction for daily life SS" by PGSAS-45 12 months after gastrectomy. The body weight ratio and PNI were better in the LLR group than in the LADG group 6 and 12 months after gastrectomy. Regarding QOL and the nutritional status, LLR based on SNNS is recommended for patients with nonindication for ESD for early gastric cancer.

\section{Compliance with ethical standards}

Conflict of interest None of the authors has any financial conflicts of interest regarding the present study.

Ethical approval All procedures followed were in accordance with the ethical standards of the responsible committee on human experimentation (institutional and national) and with the Helsinki Declaration of 1964 and later versions. The Ethics Committee of Kagoshima University and all patients provided written informed consent for the use of their information.

\section{References}

1. Giuliano AE, Kirgan DM, Guenther JM, Morton DL. Lymphatic mapping and sentinel lymphadenectomy for breast cancer. Ann Surg. 1994;220(3):391-8 discussion 398-401.

2. Morton DL, Wen DR, Wong JH, Economou JS, Cagle LA, Storm FK, et al. Technical details of intraoperative lymphatic mapping for early stage melanoma. Arch Surg. 1992;127(4):392-9.

3. Aikou T, Higashi H, Natsugoe S, Hokita S, Baba M, Tako S. Can sentinel node navigation surgery reduce the extent of lymph node dissection in gastric cancer? Ann Surg Oncol. 2001;8(9 Suppl):90S-3S.

4. Hiratsuka M, Miyashiro I, Ishikawa O, Furukawa H, Motomura K, Ohigashi H, et al. Application of sentinel node biopsy to gastric cancer surgery. Surgery. 2001;129(3):335-40.

5. Uenosono Y, Natsugoe S, Ehi K, Arigami T, Hokita S, Aikou T. Detection of sentinel nodes and micrometastases using radioisotope navigation and immunohistochemistry in patients with gastric cancer. Br J Surg. 2005;92(7):886-9.

6. Kitagawa Y, Takeuchi H, Takagi Y, Natsugoe S, Terashima M, Murakami N, et al. Sentinel node mapping for gastric cancer: a prospective multicenter trial in Japan. J Clin Oncol. 2013;31(29):3704-10.

7. Nakada K, Ikeda M, Takahashi M, Kinami S, Yoshida M, Uenosono $\mathrm{Y}$, et al. Characteristics and clinical relevance of postgastrectomy syndrome assessment scale (PGSAS)-45: newly 
developed integrated questionnaires for assessment of living status and quality of life in postgastrectomy patients. Gastric Cancer. 2015;18(1):147-58.

8. Terashima M, Tanabe K, Yoshida M, Kawahira H, Inada T, Okabe $\mathrm{H}$, et al. Postgastrectomy Syndrome Assessment Scale (PGSAS)45 and changes in body weight are useful tools for evaluation of reconstruction methods following distal gastrectomy. Ann Surg Oncol. 2014;21(Suppl 3):S370-378.

9. Inada T, Yoshida M, Ikeda M, Yumiba T, Matsumoto H, Takagane A, et al. Evaluation of QOL after proximal gastrectomy using a newly developed assessment scale (PGSAS-45). World J Surg. 2014;38(12):3152-62.

10. Namikawa T, Hiki N, Kinami S, Okabe H, Urushihara T, Kawahira $\mathrm{H}$, et al. Factors that minimize postgastrectomy symptoms following pylorus-preserving gastrectomy: assessment using a newly developed scale (PGSAS-45). Gastric Cancer. 2015;18(2):397-406.

11. Takiguchi $\mathbf{N}$, Takahashi M, Ikeda M, Inagawa S, Ueda S, Nobuoka $\mathrm{T}$, et al. Long-term quality-of-life comparison of total gastrectomy and proximal gastrectomy by postgastrectomy syndrome assessment scale (PGSAS-45): a nationwide multi-institutional study. Gastric Cancer. 2015;18(2):407-16.

12. Onodera T, Goseki N, Kosaki G. Prognostic nutritional index in gastrointestinal surgery of malnourished cancer patients. Nihon Geka Gakkai Zasshi. 1984;85(9):1001-5.

13. Pinato DJ, North BV, Sharma R. A novel, externally validated inflammation-based prognostic algorithm in hepatocellular carcinoma: the prognostic nutritional index (PNI). Br J Cancer. 2012;106(8):1439-45.

14. Kanda M, Fujii T, Kodera Y, Nagai S, Takeda S, Nakao A. Nutritional predictors of postoperative outcome in pancreatic cancer. Br J Surg. 2011;98(2):268-74.

15. Jeon HG, Choi DK, Sung HH, Jeong BC, Seo SI, Jeon SS, et al. Preoperative prognostic nutritional index is a significant predictor of survival in renal cell carcinoma patients undergoing nephrectomy. Ann Surg Oncol. 2016;23(1):321-7.

16. Sakurai K, Tamura T, Toyokawa T, Amano R, Kubo N, Tanaka H, et al. Low preoperative prognostic nutritional index predicts poor survival post-gastrectomy in elderly patients with gastric cancer. Ann Surg Oncol. 2016;23(11):3669-766.

17. Migita K, Takayama T, Saeki K, Matsumoto S, Wakatsuki K, Enomoto K, et al. The prognostic nutritional index predicts longterm outcomes of gastric cancer patients independent of tumor stage. Ann Surg Oncol. 2013;20(8):2647-54.

18. Adachi Y, Shiraishi N, Kitano S. Modern treatment of early gastric cancer: review of the Japanese experience. Dig Surg. 2002;19(5):333-9.

19. Japanese Gastric Cancer Association. Japanese gastric cancer treatment guidelines 2018 (ver. 5). Tokyo: Kanehara-shuppan; 2018.

20. Goto O, Takeuchi H, Kawakubo H, Sasaki M, Matsuda T, Matsuda $\mathrm{S}$, et al. First case of non-exposed endoscopic wall-inversion surgery with sentinel node basin dissection for early gastric cancer. Gastric Cancer. 2015;18(2):434-9.

21. Inoue H, Ikeda H, Hosoya T, Yoshida A, Onimaru M, Suzuki M, et al. Endoscopic mucosal resection, endoscopic submucosal dissection, and beyond: full-layer resection for gastric cancer with nonexposure technique (CLEAN-NET). Surg Oncol Clin N Am. 2012;21(1):129-40.

22. Natsugoe S, Arigami T, Uenosono Y, Yanagita S. Novel surgical approach based on the sentinel node concept in patients with early gastric cancer. Ann Gastroenterol Surg. 2017;1(3):180-5.

23. Arigami T, Uenosono Y, Yanagita S, Okubo K, Kijima T, Matsushita $\mathrm{D}$, et al. Clinical application and outcomes of sentinel node navigation surgery in patients with early gastric cancer. Oncotarget. 2017;8(43):75607-16.

24. Fujita J, Takahashi M, Urushihara T, Tanabe K, Kodera Y, Yumiba T, et al. Assessment of postoperative quality of life following pylorus-preserving gastrectomy and Billroth-I distal gastrectomy in gastric cancer patients: results of the nationwide postgastrectomy syndrome assessment study. Gastric Cancer. 2016;19(1):302-11.

25. Takahashi M, Terashima M, Kawahira H, Nagai E, Uenosono Y, Kinami S, et al. Quality of life after total vs distal gastrectomy with Roux-en-Y reconstruction: use of the Postgastrectomy Syndrome Assessment Scale-45. World J Gastroenterol. 2017;23(11):2068-76.

26. Kobayashi D, Kodera Y, Fujiwara M, Koike M, Nakayama G, Nakao A. Assessment of quality of life after gastrectomy using EORTC QLQ-C30 and STO22. World J Surg. 2011;35(2):357-64.

27. Kinami S, Takahashi M, Urushihara T, Ikeda M, Yoshida M, Uenosono $\mathrm{Y}$, et al. Background factors influencing postgastrectomy syndromes after various types of gastrectomy. World J Clin Cases. 2018;6(16):1111-20.

28. Furukawa H, Ohashi M, Honda M, Kumagai K, Nunobe S, Sano $\mathrm{T}$, et al. Preservation of the celiac branch of the vagal nerve for pylorus-preserving gastrectomy: is it meaningful. Gastric Cancer. 2018;21(3):516-23.

29. Isozaki H, Matsumoto S, Murakami S, Takama T, Sho T, Ishihara K, et al. Diminished gastric resection preserves better quality of life in patients with early gastric cancer. Acta Med Okayama. 2016;70(2):119-30.

30. Kawamura M, Nakada K, Konishi H, Iwasaki T, Murakami K, Mitsumori N, et al. Assessment of motor function of the remnant stomach by (1)(3)C breath test with special reference to gastric local resection. World J Surg. 2014;38(11):2898-903.

Publisher's Note Springer Nature remains neutral with regard to jurisdictional claims in published maps and institutional affiliations. 